\title{
APPLICATION OF AN EVOLUTIONARY ALGORITHM TO REDUCE THE COST OF STRENGTHENING OF TIMBER BEAMS
}

\author{
FRANCISCO B. VARONA, DAVID BRU-ORTS, FRANCISCO J. BAEZA \& SALVADOR IVORRA \\ Department of Civil Engineering, University of Alicante, Spain.
}

\begin{abstract}
The present paper describes the application of an evolutionary algorithm to the optimum design of the reinforcement of timber beams using FRP laminates and sheets. The objective function is the material cost of the strengthening and is subjected to ten constraints derived from the ultimate limit states for flexural and shear behaviour as well as the serviceability limit states. A genetic algorithm is used and the optimization problem is transformed into an unconstrained one by means of an adaptive penalty function. The design variables are the CFRP and GFRP mechanical properties and dimensions and they are encoded in a binary chromosome: type of composite material (CFRP or GFRP), reinforcement mechanical properties and geometric configuration. The search space for the minimum cost consists of 65 billion possible solutions. The crossover operator switches randomly between a fenotype crossover and flat crossover. An adaptive mutation scheme has been as well as an elitism criterion. The algorithm has been used for obtaining optimum designs in several specific load and geometry cases of glued laminated timber beams. The objective is finding whether there are specific reinforcement configurations more feasible for a certain loading situations: short or long beams and lower or higher loading increments. Five cases have been analysed. In the first three cases the length of the beams has constant values of 2, 2.5 and $3 \mathrm{~m}$, whereas the value of loading was variable. In the latter case, the value of the load was fixed and the length of the beam was variable. The analysis of the results shows that the GFRP reinforcement is more efficient than CFRP for designs governed by shear failure, whereas CFRP is more effective in the case of flexural failure and deflection controlled strengthening of timber beams.

Keywords: adaptive operators, FRP strengthening, genetic algorithm, structural optimization, timber structures
\end{abstract}

\section{INTRODUCTION}

Although the use of wood as a building material is ancient, nowadays it still presents good structural qualities compared to steel and concrete materials. It stress ratio to specific weight makes it suitable for one way floors and, in particular, wood beams without knots or cracks have high values of compressive and tensile strength. However, elastic modulus and shear strength have very low values compared with steel materials (Triantafillou [1]). Nowadays, building reutilization and the current technical standards lead to an increase in service loads and to a decrease of the maximum deflection limits. In order to improve the structural safety and reliability of structural wood systems in existing buildings, composite-based reinforcement techniques are demanded. In this regard, fibre reinforced polymers (FRP) are an adequate alternative to improve structural capacity (Bru et al. [2]). This study is aimed at reaching and optimum design of the CFRP and GFRP reinforcement of wood beams by means of a genetic algorithm. Genetic algorithms (GAs) have been thoroughly used as an alternative to traditional structural optimization methods. GAs were introduced in the 70's by Holland [3]. Concerning the optimum design of the reinforcement for retrofitting of concrete structures, GAs have proven to be a robust technique, as shown in Perera and Varona [4]. Contrary to mathematical programming based optimization methods, GAs are of a probabilistic nature. They are able to handle groups of design points simultaneously and it is also possible to handle continuous and discrete variables. Their application does not need any 
explicit algebraic formulation of the objective functions and constraint functions and since they do not depend on gradient information, it is not necessary to perform a sensitivity analysis of these functions. Those are their principal advantages over mathematical programming based optimization. GAs are based on the Darwinian principle of evolution, in which the most feasible individuals within a generation are most likely to survive and pass their genetic material on to the next generation. Among their principal advantages, GAs are easily implemented and programmed and, given enough computation time, are always capable of reaching the global optimum. This can be justified because, as noted above, they are able to analyse simultaneously a wide range of possible solutions randomly generated, thus being less sensible to converge to local optima. Other heuristic optimization techniques, such as ant colony optimization and particle swarm optimization have not yet proven as robust as GAs for structural optimization.

\section{MECHANICAL PROPERTIES OF MATERIALS}

The study of the mechanical properties of the materials used in this research was based on the standard ASTM D3039/D3039M for glass fibre reinforced polymer (GFRP) laminates (Bru et al. [5]). These properties were obtained for bidirectional laminate $\left(0 / 90^{\circ}\right.$ fibre orientation) and for different values of dosage. In this research, weight dosage values of $1 / 1$ were selected, for woven type E glass fibre with $440 \mathrm{~g} / \mathrm{m}^{2}$ weight (213/217) and an epoxy resin supplied by SICOMIN Composites, type SR 5550 and SD 5503. The geometrical and mechanical properties for GFRP laminates are given in Table 1.

In Table $1, e_{r}$ is the equivalent thickness of the laminate; $V_{f}$ and $V_{m}$ are the volume fraction of the glass fibre and the matrix, respectively; $E$ is the elastic modulus of the equivalent laminate; and $f_{u, f}$ is the tensile strength of the equivalent laminate. Other important input used in the genetic algorithm is the cost of the materials. For Sicomin epoxy resin, $34.5 € / \mathrm{m}^{2}$ has been considered. For glass fibre fabric, the following values have been considered: ULE630, 1.81 $€ / \mathrm{m}^{2}$; BXE300, $1.62 € / \mathrm{m}^{2}$; BXE315, $2.29 € / \mathrm{m}^{2}$; BXE446, $1.98 € / \mathrm{m}^{2}$; BXE600, $2.33 € / \mathrm{m}^{2}$; BXE800, $2.92 € / \mathrm{m}^{2}$; BE440, $1.67 € / \mathrm{m}^{2} ; \mathrm{BE} 850,2.74 € / \mathrm{m}^{2}$.

In the case of carbon fibre reinforced polymers (CFRP), Sika-CarboDur laminates were selected. The elastic modulus was $170 \mathrm{GPa}$ and the tensile strength $f_{u, f}$ was $2300 \mathrm{MPa}$. The laminates were supplied with a thickness of $1.2 \mathrm{~mm}$ (case 50 and $80 \mathrm{~mm}$ wide laminates) and

Table 1: Mechanical properties of GFRP laminates.

\begin{tabular}{llllllll}
\hline Material & $\begin{array}{l}\text { Fibre weight } \\
\mathrm{g} / \mathrm{m}^{2}\end{array}$ & $\begin{array}{l}\text { Orient. } \\
\mathrm{o}\end{array}$ & $\begin{array}{l}e_{r} \\
\mathrm{~mm}\end{array}$ & $\begin{array}{l}V_{f} \\
\%\end{array}$ & $\begin{array}{l}V_{m} \\
\%\end{array}$ & $\begin{array}{l}E \\
\mathrm{~N} / \mathrm{mm}^{2}\end{array}$ & $\begin{array}{l}f_{u f f} \\
\mathrm{~N} / \mathrm{mm}^{2}\end{array}$ \\
\hline GF-ULE & 630 & 0 & 0.797 & 37.2 & 62.8 & 27823 & 426 \\
GF-BXE & 300 & +-45 & 0.718 & 17.7 & 82.3 & 14721 & 225 \\
GF-BXE & 315 & +-45 & 0.724 & 18.6 & 81.4 & 15317 & 234 \\
GF-BXE & 446 & +-45 & 0.765 & 26.4 & 73.6 & 20518 & 314 \\
GF-BXE & 600 & +-45 & 0.793 & 35.5 & 64.5 & 26632 & 407 \\
GF-BXE & 800 & +-45 & 0.815 & 47.3 & 52.7 & 34573 & 529 \\
GF-BE & 440 & $0 / 90$ & 0.671 & 13.0 & 87.0 & 11545 & 176 \\
GF-BE & 600 & $0 / 90$ & 0.718 & 17.7 & 82.3 & 14721 & 225 \\
GF-BE & 850 & $0 / 90$ & 0.760 & 25.1 & 74.9 & 19684 & 301 \\
\hline
\end{tabular}


$1.4 \mathrm{~mm}$ (for 100 and $120 \mathrm{~mm}$ wide laminates). These correspond to laminate models $512 \mathrm{E}$ $(31.00 € / \mathrm{m}), 812 \mathrm{E}(47.10 € / \mathrm{m}), 1014 \mathrm{E}(69.10 € / \mathrm{m})$ and $1214 \mathrm{E}(83.20 € / \mathrm{m})$, respectively.

The elastic properties of the timber beams were obtained from the Spanish standard, CTEDB-SE-M, whereas the plastic properties were based on previous research [6]. In this way, average value of ultimate compression strain for timber beams is taken equal to 0.01 . Currently the software is only implemented with homogenous and nonhomogeneous glulam properties, but different kind of wood and reinforcement materials will be available shortly.

\section{STRUCTURE OF THE GENETIC ALGORITHM}

This section presents the formulation of the structural strengthening optimization problem, its transformation into an unconstrained one, the definition of the genetic algorithm and its operators and the treatment of the different constraints.

\subsection{Formulation of the structural optimization problem}

The general formulation of an optimization problem is to minimize an objective function subjected to a set of constraint functions, as shown in eqns (1), (2). In this case the objective function, noted as $f(x)$, was the cost of the reinforcement materials:

$$
\begin{gathered}
\text { Minimize } f(x)=C_{C F R P}+C_{G F R P} . \\
\text { subjected to } g_{i}(x) \leq 0, \quad i=1,2, \ldots, 10 .
\end{gathered}
$$

where $C_{C F R P}$ is the cost of the CFRP laminates, $C_{G F R P}$ is the cost of the GFRP and $g_{i}(x)$ are the constraints considered for this problem.

The first seven constraints deal with ultimate limit states (ULS) of the retrofitted design. Constraint $g_{1}(x)$ corresponds to the bending capacity of the wood beam at the point of maximum moment along the reinforced zone. Constraint $g_{2}(x)$ corresponds to the bending capacity at the point of maximum moment along the unreinforced zone. Constraints $g_{3}(x)$ and $g_{4}(x)$ correspond, respectively, to the tension failure of the CFRP laminate and the GFRP sheet used for flexural reinforcement at the point of maximum moment. And additional constraint $g_{5}(x)$ handles the ultimate stress of the CFRP before delamination occurs at the end of the laminate. Constraint $g_{6}(x)$ corresponds to the shear capacity of the reinforced wood beam at the point of maximum shear force near the supports. Constraint $g_{7}(x)$ corresponds to the shear capacity of the timber beam along the zone without shear reinforcement.

Constraint $g_{8}(x)$ assesses the serviceability limit state (SLS) of vertical deformations. Constraints $g_{9}(x)$ and $g_{10}(x)$ refer to geometric limitations concerning the available beam width for installing the CFRP laminates (next to one another) and the available beam depth for installing the GFRP sheets, respectively. Figure 1 shows the locations where some of the previous design constraints are checked.

\subsection{Formulation of an unconstrained optimization problem}

The constrained optimization problem was transformed into an unconstrained one. This was done by creating a penalty function $P(x, t)$, which multiplied the original objective function $f(x)$. The penalty function depends on the degree of violation of each of the constraints as 


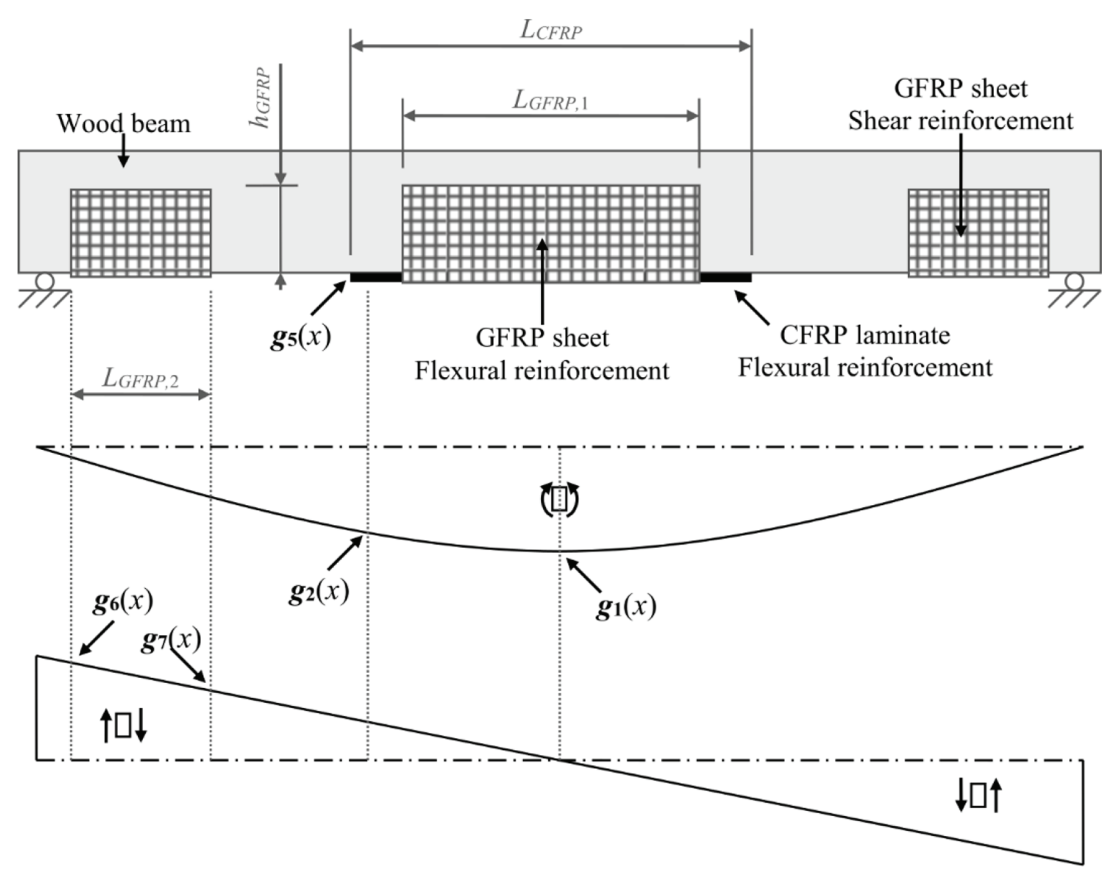

Figure 1: Assessment points of the constraints in the structural optimization problem.

well as the generation number $t$. The unconstrained optimization problem was thus rewritten in eqn. (3):

$$
\text { Minimize } \Phi(x, t)=f(x) P(x, t) .
$$

The genetic algorithm starts with a randomly generated population of 100 individuals, each encoding one possible solution. This population becomes the first generation $(t=1)$, which consists of $j=1,2, \ldots, 100$ individuals. Each one of these consists of a binary string (Fig. 2) that encodes the reinforcement: type and number of CFRP laminates and length of the CFRP reinforced zone $\left(L_{C F R P}\right)$; type and number of layers of GFRP sheets, fibre orientation, length and depth of reinforcement $\left(L_{G F R P, 1}, L_{G F R P, 2}\right.$ and $h_{G F R P}$, see Fig. 1). The aim of the penalty function $P(x, t)$ is the following: when a given individual-chromosome encodes an inexpensive solution which does not satisfy one or several constraints, then its cost gets penalized and the genetic algorithm is less likely to select that individual for the genetic operators.

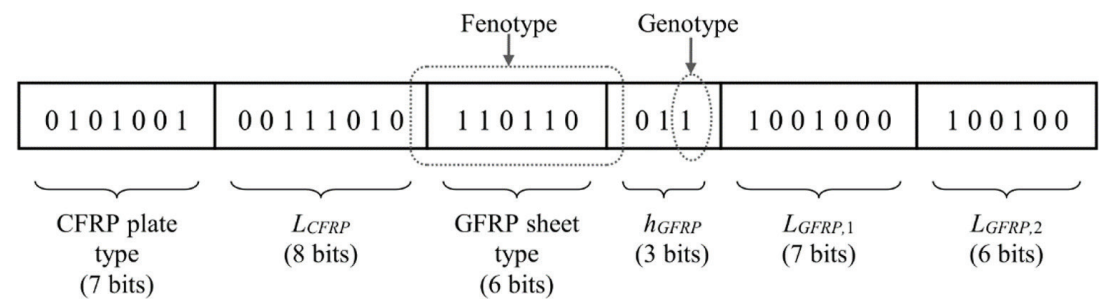

Figure 2: Example of chromosome that encodes a possible solution. 
For this optimization problem it was found that an adaptative penalty function $P(x, t)$ of the type proposed by Gen and Cheng [7] and Perera and Varona [4] worked to satisfactory results. The adaptative penalty function is calculated through eqns (4) and (5):

$$
\begin{gathered}
P(x, t)=1+\frac{1}{m} \sum_{i=1}^{m}\left(\frac{\Delta b_{i}}{b_{i}(t)}\right)^{k} . \\
\Delta b_{i}=\max \left\{0 ; g_{i}(x)-b_{i}(t)\right\} \quad \text { with } \quad b_{i}(t)=\frac{0.01}{t+1} .
\end{gathered}
$$

where a value of $k=2$ has been used in eqn (4). The parameter $b_{i}(t)$ is a penalty threshold, which, thanks to eqn (5), gets lower as the number of generations progresses.

Once function $\Phi(x, t)$ is calculated for each individual, a fitness parameter $S_{j}$ is defined for each $j$-th individual through eqn (6):

$$
S_{j}=1+\frac{\Phi_{\min , t}-\Phi_{j}(x, t)}{\Phi_{\max , t}} .
$$

where $\Phi_{\min , t}$ and $\Phi_{\max , t}$ are, respectively, the minimum and maximum values of function $\Phi(x, t)$ within the $t$-th generation.

\subsection{The genetic operators}

A genetic algorithm has three basic operators: selection, crossover and mutation. The first one, selection, depends on the fitness values. The probability of selection $p_{s, j}$ for the $j$-th individual is defined in eqn (7):

$$
p_{S, j}=\frac{S_{j}}{\sum_{j=1}^{100} S_{j}}
$$

The higher the value of $p_{S, j}$ the more likely will be the $j$-th individual eligible for reproduction and preservation of its genetic material (i.e. reinforcement type and dimensions) onto generation $t+1$. Therefore, the selected individuals become parents for generation $t+1$.

The reproduction operator is performed on a pair of parents and works combining the genetic material of the parents, creating two new individuals (possible optimum solutions) which are designated as children. This operator is also known as crossover operator. For this particular genetic algorithm a reproduction probability of $70 \%$ has been used, which means that in some cases (30\% approximately) the genetic material of the parents will not be combined and the pair of children will be identical to the pair of parents. In the rest of cases, the combination of genetic material is made randomly through two different methods: fenotype crossover and flat crossover (Radcliffe et al. [8]).

The last operator, mutation of genetic material, is not likely to produce more feasible children than their parents, but it must be used to avoid convergence to local optima. For the first 10 generations mutation probability varies from $20 \%$ to $15 \%$; between the 11-th generation and the 50-th generation, mutation decreases from $15 \%$ to $5 \%$. The mutation operator is performed at genotype level (see Fig. 2), whereas the crossover operator could work at a fenotype level. 
From the 51-th generation onwards, mutation is set at a minimum of 5\% but adaptative mutation scheme was added, making the GA able to detect whether there is little genetic diversity within a given $t$-th generation. This could happen in the event of converging to a local optimum. The genetic diversity $D_{t}$ of generation $t$ is defined as the quotient of the maximum value of the penalized objective function within the population $\Phi_{\text {max }, t}$ and its mean value $\Phi_{\text {mean }, t}$. Depending on $D_{t}$ mutation probability will be corrected as shown in eqn (8):

$$
\text { mutation probability }=\left\{\begin{array}{lll}
13 \%, & \text { if } D_{t}=1 \\
10 \%, & \text { if } 1<D_{t} \leq 1.05 \\
8 \%, & \text { if } 1.05<D_{t} \leq 1.1
\end{array} .\right.
$$

Finally, an elitism criterion has been applied, which means that generation $t+1$ will be formed by the best individuals from the group that includes the parents selected from generation $t$ and their children (i.e. if a child is not a better solution for the optimization problem than a given parent, it does not enter generation $t+1$ ).

\section{DESIGN CONSTRAINTS}

To perform this research, two standards have been used to study bending and shear behaviour of reinforced timber beams: the Spanish standard CTE-DB SE-M and the Italian standard CNR DT201. Besides, for analysing the delamination failure, several previous research works were addressed as well. These design recommendations are based on limit-states design principles and allow plastic behaviour in compression. This approach sets acceptable levels of safety against the occurrence of both serviceability limit states and ultimate limit states. To assess these limit states, certain values for the design loading and the design strength of the materials must be assumed. Load factors and strength reduction factors stated are the ones in Spanish standard (which is harmonized to the European standard Eurocode 5). For example, eqn (9) shows the bending strength $f_{w d}$ for timber beams:

$$
f_{w d}=k_{\text {mod }} \cdot k_{s y s} \cdot k_{h} \cdot \frac{f_{w k}}{\gamma_{m}} .
$$

The algorithm automatically selects the characteristic strength $f_{w k}$ of the wood according to its strength class. The software also selects the correct load factor $k_{\text {mod }}$ according the load duration, the load sharing factor $k_{s y s}$, the height factor $k_{h}$ and the material partial safety factor $\gamma_{m}$. Other factors related to the type of load (dead load, variable load, etc.) are also used in the design application.

In the assessment of constraints, $g_{1}(x)$ and $g_{2}(x)$, which correspond to the bending capacity, the following assumptions have been considered: wood is considered an isotropic material, having tree planes of symmetry; shear effect is neglected and plane sections remain plane; the stress-strain relationships assumed for wood are elastic-plastic (in compression) and linear-elastic (in tension).

In the case of GFRP and CFRP, linear-elastic behaviour is considered for both compression and tension stress. For the case of a FRP reinforced timber beam in bending, Fig. 3 shows the stress and strain distributions of the composite cross-section. The ultimate bending moment of the section $M_{u}$ has been obtained assuming strain compatibility and equilibrium of internal forces and moments. In Fig. 3, $e_{r G}$ and $e_{r C}$ are the laminate thickness for GFRP and 


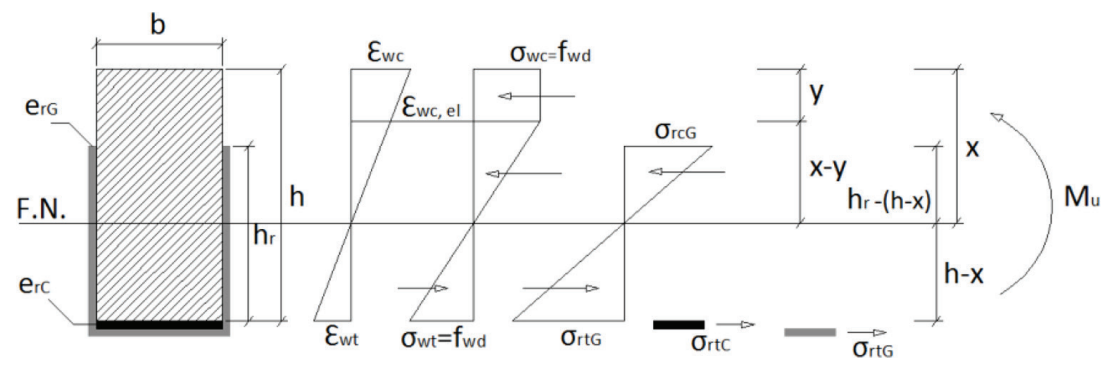

Figure 3: composite FRP-strengthened section in bending.

CFRP, respectively; $\sigma_{r c G}$ is the compression stress in the GFRP; $\sigma_{r t G}$ and $\sigma_{r t C}$ are the tensile stresses in the GFRP and in the CFRP laminate, respectively.

After calculating the flexural capacity $M_{u}$ of the strengthened timber beam and the factored value of the maximum bending moment at mid-span $M_{E d \text {, max }}$, constraint $g_{1}(x)$ can be obtained through eqn (10):

$$
M_{E d, \text { max }} \leq M_{u} \rightarrow \frac{M_{E d, \text { max }}}{M_{u}} \leq 1 \rightarrow g_{1}(x)=\left(\frac{M_{E d, \text { max }}}{M_{u}}-1\right) \leq 0 .
$$

An analogous approach must be followed with constraints $g_{2}(x)$ to $g_{10}(x)$.

Constraints $g_{3}(x)$ and $g_{4}(x)$ correspond to the tension failure of laminate. In this case, the ultimate tensile strain of wood is equal to the maximum value of the laminate strain. Therefore, the stress level of the laminates will be around $14 \%$ of its ultimate stress. Thus, these constraints are not likely to be active during the optimization process. However, in future improvements of the algorithm, voids and defects in the wood, could change this hypothesis.

Constraints $g_{5}(x), g_{6}(x)$ and $g_{7}(x)$ correspond to the shear capacity of wood beams. In these cases, two different analyses have been performed. On the one hand, the value of resisting shear force $V_{R d}$ was calculated by transforming the FRP reinforcement to equivalent wood, according to Triantafilou et al. [1], and using the formulation of Collignon-Jourawski; the ultimate strength was then calculated according to the Spanish standard. The equivalent wood thickness of the GFRP is notated as $e_{h, r G}$ and is equal to the GFRP thickness $e_{r G}$ times the quotient of the laminate elastic modulus and the wood elastic modulus. In this case, it has been assumed that no other failure mechanism such as FRP shear failure occurs prior to wood shear failure. On the other hand, the second possible failure mechanism is due to debonding of the CFRP laminate. In this case, the maximum laminated normal stress $\sigma_{r t C \text {, max }}$ was calculated according to Juvandes et al. [9], as shown in eqn (11):

$$
\sigma_{r t C, \max }=\frac{c_{1} \cdot k_{b} \cdot k_{c} \cdot \sqrt{E_{r C} \cdot e_{r C} \cdot f_{w t m, p}} \cdot k_{\mu}}{e_{r C}} .
$$

where $c_{1}, k_{c}$ and $k_{\mu}$ are experimental factors equal to $0.76,1$, and 1 , respectively; $k_{b}$ is a geometrical function; $E_{r C}$ is the elastic modulus of the CFRP laminate; and $f_{w t m, p}$ is the ultimate pull-off stress, equal to $2.5 \mathrm{MPa}$. Currently, the algorithm considers the maximum anchor length, according to the properties of the reinforcement. Moreover, this check is performed only for CFRP laminates, due to the lack of information about experimental test for debonding in wrap beams with GFRP. 
In addition to the ultimate limit states, the serviceability of a member under service loads should satisfy the provisions of Spanish standard CTE-DB-E-M. This is verified through constraint $g_{8}(x)$ for the following three cases: structural integrity, user comfort and functionality. The calculation method of these three different provisions is indicated in the Spanish standard.

Finally, constraint $g_{9}(x)$ corresponds to the ratio between the total width of the CFRP plates and that of the timber beam cross-section. In the same way, constraint $g_{10}(x)$ corresponds to the ratio between the perimeter of GFRP and the roll width of fiberglass fabric.

\section{APPLICATION OF THE GENETIC ALGORITHM}

This section shows the application of the genetic algorithm to evaluate the efficiency of different schemes of reinforcing to simply supported timber beams.

The first example consists of a $3 \mathrm{~m}$ span beam, with a $0.08 \times 0.16$ cross section (width $\times$ depth). It is a glulam GL24h timber beam subjected to a fixed distributed dead load of $0.825 \mathrm{kN} / \mathrm{m}$, plus a distributed live load. The unreinforced timber beam is able to support a live load of $2.475 \mathrm{kN} / \mathrm{m}$ according to CTE-DB-SE-M. The live load is increased at $10 \%$ intervals and the optimum reinforcing scheme for each of them is obtained with the genetic algorithm (10 runs are performed for each case). Table 2 shows the optimum designs. The notation used in Table 2 is the following: $L_{C}$ is the length of the CFRP laminate, which is centred at mid span; $H_{G}$ is the depth of the GFRP reinforcing, on the lateral faces of the timber beam; $L_{G, A}$ is the length of the GFRP from the beam ends, used for reinforcing in shear; $L_{G, C}$ is the length of the GFRP located at mid span (analogous to $L_{C}$ ); finally, the cost is given as a unit cost, comparing the total cost of reinforcing materials to that of the timber beam (hence the units, in $€ / €$ ). As it was introduced in Table 1, BXE stands for bidirectional fibres $\left( \pm 45^{\circ}\right)$ whereas ULE stands for fibres with single orientation.

When SLS are active for aesthetic reasons, the algorithm converges to an expensive solution installing CFRP laminates, which is the most effective way of increasing the inertia of the composite cross section and thus reducing the maximum vertical displacement. However, when SLS is not active, Table 2 shows that GFRP reinforcing for flexural bending is the less expensive scheme. In this case it also becomes clear that shear reinforcement is not needed

Table 2: Optimum solutions for Example 1: $3 \mathrm{~m}$ simply supported beam.

\begin{tabular}{|c|c|c|c|c|c|c|c|c|c|}
\hline & \multirow[b]{2}{*}{$\begin{array}{l}\Delta \boldsymbol{q} \\
(\%)\end{array}$} & \multicolumn{2}{|l|}{ CFRP } & \multicolumn{5}{|l|}{ GFRP } & \multirow[b]{2}{*}{$\begin{array}{l}\text { Cost } \\
(€ / €)\end{array}$} \\
\hline & & Type & $\begin{array}{l}L_{C} \\
(\mathrm{~mm})\end{array}$ & Type & $\begin{array}{l}\text { n. } \\
\text { layers }\end{array}$ & $\begin{array}{l}H_{G} \\
(\mathrm{~mm})\end{array}$ & $\begin{array}{l}L_{G, A} \\
(\mathrm{~mm})\end{array}$ & $\begin{array}{l}L_{G, C} \\
(\mathrm{~mm})\end{array}$ & \\
\hline \multirow{4}{*}{$\begin{array}{l}\text { SLS } \\
+ \\
\text { ULS }\end{array}$} & 10 & $1 \times 512 \mathrm{E}$ & 450 & ULE630 & 2 & 90 & 0 & 480 & 0.85 \\
\hline & 20 & $1 \times 512 \mathrm{E}$ & 800 & ULE630 & 3 & 90 & 0 & 730 & 1.71 \\
\hline & 30 & $1 \times 512 \mathrm{E}$ & 1120 & ULE630 & 3 & 90 & 0 & 1180 & 2.58 \\
\hline & 40 & $1 \times 512 \mathrm{E}$ & 1250 & ULE630 & 3 & 160 & 0 & 1320 & 3.53 \\
\hline \multirow{6}{*}{ ULS } & 10 & - & - & BXE300 & 1 & 90 & 0 & 370 & 0.14 \\
\hline & 20 & - & - & BXE446 & 1 & 90 & 0 & 820 & 0.32 \\
\hline & 30 & - & - & ULE630 & 1 & 90 & 0 & 1080 & 0.42 \\
\hline & 40 & - & - & ULE630 & 2 & 90 & 0 & 1280 & 1.00 \\
\hline & 50 & - & - & ULE630 & 2 & 90 & 0 & 1420 & 1.11 \\
\hline & 60 & - & - & ULE630 & 3 & 90 & 0 & 1560 & 1.83 \\
\hline
\end{tabular}


(because $L_{G, A}$ is null in all cases). Finally, for live load increments over $60 \%$ the algorithm did not find any feasible solutions: in the event of retrofitting a timber beam with the aforementioned characteristics for a live load increment over $60 \%$ its original value, strengthening solutions different from FRP materials should be taken into account

Tables 3 and 4 show the solutions obtained when applying the GA to simply supported timber beams of 2.5 and $2 \mathrm{~m}$ span, respectively. In the case of the $2.5 \mathrm{~m}$ beam, the original distributed live load for the unreinforced design was $4.125 \mathrm{kN} / \mathrm{m}$. In the case of the $2 \mathrm{~m}$ beam, the original distributed live load was $6.49 \mathrm{kN} / \mathrm{m}$.

The purpose of analysing shorter beams is forcing the algorithm to deal with designs which can be partially governed by shear failure. In the case of the $2 \mathrm{~m}$ span beam, there were no differences found between the optimum designs for ULS and SLS combined and those corresponding to ULS only; vertical deformations did not control the strengthening solution and they would not constitute critical constraints in short beams.

A remarkable result is that of the $2.5 \mathrm{~m}$ span beam retrofitted for an increase of $50 \%$ its original live load, with both ULS and SLS constraints active: this was found to be the most expensive design, needing a wider CFRP laminate as well as GFRP reinforcements for both bending and shear.

Finally, the smallest possible live load increment corresponded to the shortest beam (Table 4). FRP strengthening solutions would not be adequate for a retrofitting demanding an increase of over $30 \%$ the original distributed live load.

Next examples are of beams subjected to fixed values of dead and live distributed loads, but with increasing lengths. In example 4 the original design is the same one as in example 1: $0.08 \times 0.16 \mathrm{~m}$ rectangular cross section; glulam GL24h wood; subjected to distributed loads of 0.825 and $2.475 \mathrm{kN} / \mathrm{m}$ (dead and live values, respectively). The maximum span possible for the unstrengthened design is $3 \mathrm{~m}$.

Table 5 shows the results for increasing lengths in example 4. Again, CFRP became necessary only when SLS was active as a design constraint. Considering ULS only, the maximum span length compatible with FRP strengthening would be $3.6 \mathrm{~m}$ (a $20 \%$ higher than $3 \mathrm{~m}$ ). With that range of lengths (and for the $0.08 \times 0.16 \mathrm{~m}$ glulam GL24h cross section), shear

Table 3: Optimum solutions for Example 2: $2.5 \mathrm{~m}$ simply supported beam.

\begin{tabular}{llllllllll}
\hline \multicolumn{7}{c}{ CFRP } & \multicolumn{7}{c}{ GFRP } & \\
\cline { 2 - 8 } & $\begin{array}{llllllll}\Delta \boldsymbol{q} \\
(\%)\end{array}$ & Type & $\begin{array}{l}L_{C} \\
(\mathrm{~mm})\end{array}$ & Type & $\begin{array}{l}\text { n. } \\
\text { layers }\end{array}$ & $\begin{array}{l}H_{G} \\
(\mathrm{~mm})\end{array}$ & $\begin{array}{l}L_{G, A} \\
(\mathrm{~mm})\end{array}$ & $\begin{array}{l}L_{G, C} \\
(\mathrm{~mm})\end{array}$ & $\begin{array}{l}\text { Cost } \\
(€ / €)\end{array}$ \\
\hline \multirow{4}{*}{ SLS } & 10 & $1 \times 512 \mathrm{E}$ & 220 & ULE630 & 1 & 90 & 0 & 790 & 0.65 \\
+ & 30 & $1 \times 512 \mathrm{E}$ & 680 & ULE630 & 2 & 90 & 0 & 990 & 1.80 \\
$\mathrm{ULS}$ & 40 & $1 \times 512 \mathrm{E}$ & 1010 & ULE630 & 2 & 160 & 130 & 1190 & 3.22 \\
& 50 & $1 \times 512 \mathrm{E}$ & 1400 & ULE630 & 3 & 90 & 220 & 1450 & 4.45 \\
& 10 & - & - & BXE446 & 1 & 90 & 0 & 480 & 0.31 \\
& 20 & - & - & ULE630 & 1 & 160 & 0 & 970 & 0.65 \\
ULS & 30 & - & - & ULE630 & 2 & 90 & 130 & 1170 & 1.34 \\
& 40 & - & - & ULE630 & 3 & 90 & 220 & 1320 & 2.48 \\
& 50 & $1 \times 812 \mathrm{E}$ & 390 & ULE630 & 3 & 90 & 290 & 1430 & 3.59 \\
\hline
\end{tabular}


Table 4: Optimum solutions for Example 3: $2 \mathrm{~m}$ simply supported beam.

\begin{tabular}{llllllllll}
\hline \multicolumn{7}{c}{ CFRP } & \multicolumn{7}{c}{ GFRP } & \\
\cline { 2 - 8 } & $\begin{array}{l}\Delta \boldsymbol{q} \\
(\%)\end{array}$ & Type & $\begin{array}{l}L_{C} \\
(\mathrm{~mm})\end{array}$ & Type & $\begin{array}{l}\text { n. } \\
\text { layers }\end{array}$ & $\begin{array}{l}H_{G} \\
(\mathrm{~mm})\end{array}$ & $\begin{array}{l}L_{G, A} \\
(\mathrm{~mm})\end{array}$ & $\begin{array}{l}L_{G, C} \\
(\mathrm{~mm})\end{array}$ & $\begin{array}{l}\text { Cost } \\
(€ / €)\end{array}$ \\
\hline SLS & 5 & - & - & BXE300 & 1 & 90 & 80 & 0 & 0.09 \\
+ & 10 & - & - & ULE630 & 1 & 90 & 130 & 360 & 0.36 \\
$\mathrm{ULS}$ & 15 & - & - & BXE446 & 1 & 90 & 170 & 550 & 1.04 \\
& 20 & - & - & ULE630 & 2 & 90 & 220 & 690 & 1.33 \\
ULS & 25 & - & - & ULE630 & 2 & 90 & 250 & 790 & 1.52 \\
only & 30 & - & - & ULE630 & 3 & 90 & 310 & 910 & 2.70 \\
\hline
\end{tabular}

Table 5: Optimum solutions for Example 4: $q=2.475 \mathrm{kN} / \mathrm{m}$; original span length of $3 \mathrm{~m}$.

CFRP GFRP

\begin{tabular}{llllllllll}
\cline { 3 - 8 } & $\begin{array}{l}\Delta L \\
(\%)\end{array}$ & Type & $\begin{array}{l}L_{C} \\
(\mathrm{~mm})\end{array}$ & Type & $\begin{array}{l}\text { n. } \\
\text { layers }\end{array}$ & $\begin{array}{l}H_{G} \\
(\mathrm{~mm})\end{array}$ & $\begin{array}{l}L_{G, A} \\
(\mathrm{~mm})\end{array}$ & $\begin{array}{l}L_{G, C} \\
(\mathrm{~mm})\end{array}$ & $\begin{array}{l}\text { Cost } \\
(€ / €)\end{array}$ \\
\hline SLS & 5 & $1 \times 512 \mathrm{E}$ & 760 & ULE630 & 3 & 160 & 0 & 810 & 2.03 \\
+ & 10 & $1 \times 512 \mathrm{E}$ & 1680 & BXE800 & 3 & 160 & 0 & 1550 & 4.42 \\
$\mathrm{ULS}$ & & & & & & & & & \\
& 5 & - & - & BXE300 & 1 & 90 & 0 & 640 & 0.28 \\
$\mathrm{ULS}$ & 10 & - & - & ULE630 & 1 & 140 & 0 & 1200 & 0.67 \\
& 15 & - & - & ULE630 & 3 & 90 & 0 & 1610 & 1.33 \\
& 20 & - & - & ULE630 & 3 & 90 & 0 & 1930 & 2.29 \\
\hline
\end{tabular}

Table 6: Optimum solutions for Example 5: $q=6.49 \mathrm{kN} / \mathrm{m}$; original span length of $2 \mathrm{~m}$. CFRP GFRP

\begin{tabular}{llllllllll}
\cline { 4 - 7 } & $\begin{array}{l}\Delta L \\
(\%)\end{array}$ & Type & $\begin{array}{l}L_{C} \\
(\mathrm{~mm})\end{array}$ & Type & $\begin{array}{l}\text { n. } \\
\text { layers }\end{array}$ & $\begin{array}{l}H_{G} \\
(\mathrm{~mm})\end{array}$ & $\begin{array}{l}L_{G, A} \\
(\mathrm{~mm})\end{array}$ & $\begin{array}{l}L_{G, C} \\
(\mathrm{~mm})\end{array}$ & $\begin{array}{l}\text { Cost } \\
(€ / €)\end{array}$ \\
\hline SLS & 5 & - & - & BXE300 & 1 & 90 & 80 & 430 & 0.38 \\
+ & 10 & - & - & ULE630 & 1 & 130 & 150 & 810 & 0.89 \\
ULS & 15 & $1 \times 512 \mathrm{E}$ & 760 & ULE630 & 2 & 90 & 220 & 1100 & 3.18 \\
& 20 & $1 \times 512 \mathrm{E}$ & 1280 & ULE630 & 3 & 90 & 280 & 1340 & 5.43 \\
& 5 & - & - & BXE300 & 1 & 90 & 80 & 430 & 0.38 \\
ULS & 10 & - & - & ULE630 & 1 & 130 & 150 & 810 & 0.89 \\
& 15 & - & - & ULE630 & 2 & 90 & 220 & 1100 & 1.90 \\
& 20 & - & - & ULE630 & 3 & 90 & 280 & 1340 & 3.38 \\
\hline
\end{tabular}

strengthening would not be needed. When considering GFRP sheets for flexural reinforcement (with SLS not active), the tendency of the genetic algorithm is to start increasing the height $H_{G}$ of the ' $U$ ' sheets; however, for longer spans (with moments increasing proportionally to the square of the span), the genetic algorithm finds it more adequate to maintain a shorter height $H_{G}$ and increase the number of layers. 
Example 5 starts with the same cross section, with a short span of $2 \mathrm{~m}$ and fixed loads of $0.825 \mathrm{kN} / \mathrm{m}$ and $6.49 \mathrm{kN} / \mathrm{m}$ (dead and live, respectively). Optimum results for increasing span lengths are listed in Table 6. The most expensive solution corresponds to a design that needs reinforcement for both SLS (vertical deformations) and ULS (shear failure), with a span length increase of $20 \%$.

\section{CONCLUSIONS}

A genetic algorithm for optimum design of bending and shear FRP reinforcement of low cost timber beams has been presented. This GA serves the purpose of minimizing the material cost associated with the reinforcement materials for ULS and SLS requirements according to the Spanish standards.

Adaptive schemes for both the penalty function and the mutation operator showed adequate performance when applying the GA to this particular design problem.

The analysis of the solutions found by the GA for a set of practical examples showed that for structures with flexural failure behaviour, the ultimate load can be increased up to 50-60\% over the ultimate load for the unreinforced beam. However, for beams with shear failure controlled behaviour, the ultimate load should not be increased over $30 \%$ of the unreinforced original load, due to the failure on the supports area.

Finally, GFRP sheets should be considered not only for shear strengthening but also for flexural strengthening, since they allow reducing the amount of CFRP laminate needed and so, they allow to reduce the retrofitting costs. The GA proved effective on deciding whether this could be achieved by using higher ' $U$ ' sheets or by adding layers of FRP.

\section{ACKNOWLDEGEMENTS}

The authors express deep gratitude to GRESMES Research Group at the University of Alicante for their useful assistance. This work was partially financed by the University of Alicante by means of the GRE12-04 Research Project and Generalitat Valenciana, grant GV/2014/079.

\section{REFERENCES}

[1] Triantafillou, T.C., Shear reinforcement of wood using FRP materials. Journal of Materials in Civil Engineering, 9(2), pp. 22-25, 1997. https://doi.org/10.1061/(asce)0899-1561(1997)9:2(65)

[2] Bru, D., Baeza, F.J., Varona, F.B., García-Barba, J. \& Ivorra, S., Static and dynamic properties of retrofitted timber beams using glass fibre reinforced polymers. Materials and Structures, 49(1), pp. 181-191, 2014. https://doi.org/10.1617/s11527-014-0487-0

[3] Holland, J.H., Adaptation in natural and artificial systems, MIT Press: Cambridge, Mass., 1975.

[4] Perera, R. \& Varona, F.B., Flexural and shear design of FRP plated RC structures using a genetic algorithm. ASCE Journal of Structural Engineering, 135(11), pp. 1418-1429, 2009. https://doi.org/10.1061/(asce)0733-9445(2009)135:11(1418)

[5] Bru, D., Baeza, F.J., Varona, F.B. \& Ivorra, S., Numerical and experimental evaluation of FRP reinforcement on the mechanical behaviour of timber beams. Proceedings of the 16th European Conference on Composite Materials, pp. 1-8, 2014. 
[6] Yang, Y., Liu, J. \& Xiong, G., Flexural behaviour of wood beams strengthened with HFRP. Construction and Building Materials, 43, pp. 118-124, 2013.

https://doi.org/10.1016/j.conbuildmat.2013.01.029

[7] Gen, M. \& Cheng, R., A survey of penalty techniques in genetic algorithms. Proceedings of the 1996 International Conference on Evolutionary Computation, pp. 804-809, 1996.

[8] Radcliffe, N.J., Equivalence class analysis of genetic algorithms. Complex Systems, 5, pp. 183-205, 1991.

[9] Juvandes, L.F.P. \& Barbosa, R.M.T., Bond analysis of timber structures strengthened with FRP systems. Strain: An International Journal for Experimental Mechanics, 48, pp. 124-135, 2012.

https://doi.org/10.1111/j.1475-1305.2011.00804.x 